\title{
Criterios de valoración de trabajos científicos SEDEN
}

\section{EVALUACIÓN TRABAJOS CUANTITATIVOS}

1. CRITERIOS DE ESTRUCTURA: (Evalúan los aspectos formales del trabajo)

1.a. ORIGINALIDAD:

Aunque se trata de un concepto subjetivo ya que puede tener diferentes significados en función del conocimiento personal del evaluador, se define este criterio como "tema novedoso" o tema "poco descrito", o el tratamiento de un tema muy estudiado desde otro punto de vista, nunca o pocas veces utilizado.

\section{1.b. ENUNCIADO DE OBJETIVOS:}

Este criterio es un criterio objetivo, ya que se trata de valorar si la propuesta de estudio se responde con las conclusiones del mismo. Para esto, el evaluador debe comprobar que el objetivo del estudio no abarca supuestos que no se responden con los resultados obtenidos o que no son demostrados estadísticamente.

\section{1.c.-METODOLOGÍA:}

Este criterio se valorará en función de la estructura de trabajo científico, caracterizada por constar de Introducción (opcional), Material y Método, Resultados y Conclusiones.

En la metodología se deberían definir aspectos como la población estudiada y la muestra, así como el tipo de muestreo utilizado. Se debería también especificar si el estudio es descriptivo 0 experimental y enunciar los métodos estadísticos utilizados.

\section{1.d. CLARIDAD DE RESULTADOS:}

Este criterio valorará si se entienden fácilmente los resultados, sin necesidad de leer todo el trabajo. Los resultados deben ser representados numéricamente y no deben ser interpretados.

\section{1.e. TÍTULO:}

En el título se valorará si el mismo se corresponde con el desarrollo del trabajo, o si la lectura del trabajo responde a las expectativas que plantea el título.

\section{CRITERIOS DE CONTENIDO:}

\section{2.a. APLICACIÓN PRÁCTICA E INTERÉS PARA LA ENFERMERÍA NEFROLÓGICA. \\ Aunque se trata de un criterio muy subjetivo, el evaluador intentará determinar si los resultados del estudio son aplicables por enfermería de forma autónoma, teniendo en cuenta si esta aplicación re- percute en beneficio del paciente.}

Por otro lado, valorará si el estudio en cuestión es de interés para la enfermería nefrológica en su conjunto, independientemente de la actividad que se desarrolle en cualquiera de sus campos.

\section{EVALUACIÓN TRABAJOS CUALITATIVOS}

1. CRITERIOS DE ESTRUCTURA: (Evalúan los aspectos formales del trabajo)

1.a. ORIGINALIDAD:

Aunque se trata de un concepto subjetivo ya que puede tener diferentes significados en función del conocimiento personal del evaluador, se define este criterio como "tema novedoso" o tema "poco descrito", o el tratamiento de un tema muy estudiado desde otro punto de vista, nunca o pocas veces utilizado.

\section{1.b. ENUNCIADO DE OBJETIVOS:}

Este criterio es un criterio objetivo, ya que se trata de valorar si la propuesta de estudio se responde con las conclusiones del mismo. Para esto, el evaluador debe comprobar que el objetivo del estudio no abarca supuestos que no se responden con los resultados obtenidos.

1.c. METOdOLOGÍA:

Este criterio se valorará en función de la estructura de trabajo científico, caracterizada por constar de introducción (opcional) además de definir los 
instrumentos cualitativos utilizados como la observación, número de participantes, tipo de entrevista realizada: informal o semiestructurada, registro de los datos y análisis de los documentos.

\section{1.d. CLARIDAD DE RESULTADOS:}

Este criterio valorará si se entienden fácilmente los resultados, sin necesidad de leer todo el trabajo.

1.e. TÍTULO:

En el título se valorará si el mismo se corresponde con el desarrollo del trabajo, o si la lectura del trabajo responde a las expectativas que plantea el título.

\section{CRITERIOS DE CONTENIDO:}

\section{2.a. APLICACIÓN PRÁCTICA E INTERÉS PARA LA ENFERMERÍA NEFROLÓGICA.}

Aunque se trata de un criterio muy subjetivo, el evaluador intentará determinar si partiendo de una perspectiva holística de los datos del estudio estos contribuyen a una mejor compresión de los procesos de salud y teniendo en cuenta si esta aplicación repercute en beneficio del paciente.

Por otro lado, valorará si el estudio en cuestión es de interés para la enfermería nefrológica en su conjunto, independientemente de la actividad que se desarrolle en cualquiera de sus campos.

\section{PROCESO DE SELECCIÓN DE TRABAJOS}

Los trabajos presentados al congreso de la SEDEN, son clasificados en la secretaría de la sociedad según su temática, en los siguientes grupos o áreas de interés diferentes:

\section{- Hemodiálisis}

- Diálisis peritoneal

- Trasplante renal

- Atención integral

- Enfermedad Renal Crónica Avanzada (ERCA)

Una vez clasificados los trabajos, son enviados a los miembros del Comité Seleccionador, que esta formado por grupos de "expertos" en estas cinco áreas, de forma que cada trabajo sea valorado por cuatro evaluadores diferentes.

Junto a las copias anónimas de los trabajos, se enviarán a los evaluadores unas planillas en las que deben ano- tar las puntuaciones que adjudican a cada uno de los criterios antes descritos, según la siguiente escala de puntuación:

- Criterios de estructura: Cada criterio se puede puntuará con el siguiente baremo..

1.a. ORIGINALIDAD: se puntuará de 0 a 2’5 puntos.

1.b. ENUNCIADO DE OBJETIVOS: se puntuará de 0 a 2 puntos.

1.c. METODOLOGÍA: se puntuará de 0 a 2 puntos.

1.d. CLARIDAD DE RESULTADOS: se puntuará de 0 a 2'5 puntos.

1.e. TÍTULO: se puntuará de 0 a 1 puntos.

- Criterios de contenido: (se puntuará de $\mathbf{1}$ a $\mathbf{1 0}$ puntos)

Las planillas con las puntuaciones serán enviadas a la SEDEN, y a un coordinador que será designado en cada grupo de "expertos", cuya función será detectar diferencias significativas entre puntuaciones adjudicadas por diferentes evaluadores, para después de leer el trabajo en cuestión, contactar con los evaluadores implicados, interesándose por los motivos de la diferencia de valoración.

La puntuación que cada evaluador adjudica al trabajo, será calculada por la Secretaría de la SEDEN de la siguiente forma: se sumarán todas las puntuaciones adjudicadas a los criterios, y este resultado se dividirá entre dos para que la nota resultante sea sobre diez.

De esta forma se garantiza que la mitad de la nota alcanzada se debe al interés del trabajo para la enfermería nefrológica y a su aplicación práctica.

Posteriormente, se hará la media entre las cuatro puntuaciones diferentes adjudicadas a cada trabajo, obteniendo así la puntuación final, que será la base para la adjudicación de los diferentes premios y para la confección del programa científico del congreso, aceptándose para su exposición oral los trabajos mejor puntuados, valorando la aceptación de los trabajos menos puntuados para su exposición en formato póster.

La adjudicación de los diferentes premios y la confección del programa científico del congreso, tendrá lugar en una reunión conjunta entre la Junta Directiva de la SEDEN y los cuatro coordinadores del comité seleccionador, que supervisarán este proceso ante las puntuaciones adjudicadas por la totalidad del comité seleccionador. 


\section{EVALUACIÓN DE TRABAJOS “POSTER”}

Los trabajos que inicialmente se presentan resumidos para su exposición en formato póster, serán evaluados por el comité junto a los presentados para su exposición oral.

Los trabajos presentados en este formato, inicialmente no optan a premio debido a las limitaciones que presenta el resumen del trabajo para lograr una valoración homogénea con el resto de trabajos.

El comité de selección de trabajos tiene la potestad de considerar la aceptación de un trabajo para su presentación en formato póster, aunque haya sido presentado para comunicación oral y viceversa. Así mismo la Organización se reserva el derecho de decidir si las Comunicaciones Póster se presentarán a pie de póster o no.
El evaluador, solamente debe consignar en la casilla "NOTA" de la planilla de puntuación, si considera el trabajo en cuestión "APTO" o "NO APTO" para su presentación en nuestro congreso, si basándose en su visión personal, entiende que cumple con los criterios mínimos de calidad para ser aceptado.

Los trabajos que finalmente sean aceptados y presentados en este formato, se someterán a una segunda evaluación, tras el envío del poster en formato $p d f$., en el mes de Septiembre. Y durante el congreso serán seleccionados los premiados.

Para esta segunda valoración los evaluadores cumplimentarán las planillas de puntuación correspondientes, puntuando de $\mathbf{1}$ a $\mathbf{1 0}$ los siguientes criterios:

- Interés para la práctica de la enfermería.

- Metodología e interés científico

- Originalidad

- Calidad artística. 